\author{
Margarita Menéndez, Institute of Physical-Chemistry Rocasolano (CSIC) and \\ Ciber of Respiratory Diseases (CIBERES; ISCIII), Madrid, Spain.
}

\title{
Abstract:
}

Molecular recognition is a fundamental phenomenon underpinning almost all aspects of biological processes. Associated energy changes result in release or absorption of heat that can be measured, providing valuable information about the interaction specific features. Isothermal titration calorimetry (ITC) is a label-free binding assay which measures the affinity, stoichiometry, and thermodynamics of molecular interactions from the reaction heat. It is considered the gold-standard technique owing to its unique capacity to provide a complete thermodynamic and even kinetic profile of the interaction in a single experiment, thus giving a detailed understanding of driving forces and underlying processes. Moreover, ITC can be used to characterize complex systems hardly amenable using other techniques and also enzyme catalyzed reactions. Consequently, ITC is being used to study a wide range of interactions mediated by proteins, nucleic acids, lipids, oligosaccharides and other natural or synthetic molecules, and has become a key component of drug discovery platforms.

Key words:

Isothermal titration calorimetry; molecular recognition; binding thermodynamics; binding kinetics; thermodynamic signature; drug design; enzyme kinetics; biomolecular interactions.

\section{Key Concepts:}

Molecular recognition via non-covalent interactions is of fundamental importance to most processes occurring within living organisms.

ITC provides a general, quantitative approach to analyze the thermodynamics and kinetics of such recognition events, and to characterize enzyme mediated reactions. new insights into the molecular nature of molecular interactions being studied. 
The kinetics of binding events is also central to understand not only physiological processes but also drug efficacy since equilibrium states often may not be stablished in vivo

Understanding the kinetic behavior of enzymes is important to understand biochemical pathways, and is also a yielding field for drug discovery and development, and biotechnology.

\section{Introduction:}

The unique importance of studying molecular interactions arises from the fact that nearly every physiological or pathological event, as well as therapeutic intervention, is triggered by or depends critically on non-covalent binding of two or more molecules in a stoichiometric manner. Eventually, complexes may react to form product/s when the receptor is an enzyme and the ligand a substrate. Over past few decades, an outburst of high resolution structures of biomolecular complexes have allowed a better understanding of how molecules interact but no why they do so, which implies achieving a quantitative description of the energetic forces and mechanisms governing complex formation or substrate transformation. Isothermal titration calorimetry (ITC) can provide the thermodynamic and kinetic data required for such understanding as it directly measures, as a function of time, the heat exchange associated to a chemical reaction triggered by the mixing of two or more components at constant pressure and temperature. As absorption or release of heat accompanies almost every chemical reaction, ITC is a quantitative analytical tool of general application. In addition, there is no need to chemically modify or immobilize the reactants or use extrinsic probes, and it is unaffected by the spectroscopic properties of the samples. Therefore, ITC can be applied to the study of complex systems hardly amenable by other techniques, including the use of physiological reagents and conditions. Thermodynamic information can in turn to be used to interpret the data at molecular level, together with information from other techniques (e.g. X-Ray, NMR, MDS, statistical thermodynamics, etc.). All these issues are briefly reviewed in this article. Examples from literature of the different methodologies and applications for thermodynamic and kinetic studies are gathered together, with the aim of illustrating the current state-of-the-art of ITC and guiding unfamiliar readers to further explore specific subjects. Methodological aspects key to optimal design of ITC experiments, reliable data analysis or critical interpretation of results are specifically discussed and, lastly, practical tips are provided. See also: DOI: 10.1002/9780470015902.a0003010.pub3; DOI: 10.1002/9780470015902.a0027015; DOI: 10.1002/9780470015902.a0001341; DOI: 10.1038/npg.els.0001271; DOI: 10.1002/9780470015902.a0000716.pub2 for related readings.

\section{ITC Operational Principle and Instrumentation}

<insert> Modern commercial ITCs operate on the dynamic power compensation principle. They are composed of two identical (reference and sample) cells surrounded by an adiabatic jacket, and a syringe for titrant addition which also works as stirring device (Figure 1a). The cells are connected by sensitive thermocouple circuits that detect the difference of temperature between them, and between cells and jacket. 
Heaters located in both cells are activated when required to maintain identical temperatures among all components. The feedback system continuously applies a fixed power to the reference cell which determines the baseline level, and the measured signal $(\mu \mathrm{cal} / \mathrm{s})$ is the compensating feedback power applied to the sample cell to maintain constant (close to zero) the temperature difference with the reference cell (Figure 1b, top). When a reaction is started by computer-controlled injection of the reactant in the syringe into the sample cell loaded with the other reactant, the reaction heat causes a difference of temperature between the cells, and the feedback system either lowers (exothermic reactions) or raises (endothermic reactions) the thermal power to compensate the temperature unbalance. Thermal equilibrium is restored when the reaction ends and the initial baseline is recovered. Protocols applied in ITC studies differ only in the way the experiment is planned and not in the way the instrument is used (Velázquez-Campoy et al., 2004). References describing most common protocols are gathered in Table 1.

Improvements in modern ITCs have been in the direction of developing increasingly sensitive $(0.01-0.02 \mu \mathrm{cal}$ detection limit) easy-to-use instruments, which allow precise titrations using small amounts of samples $(0.2-1.5 \mathrm{ml}$ cell volume) in a wide range of temperatures $\left(2\right.$ to $80^{\circ} \mathrm{C}$ ). Automated versions of the standard instruments are also available for high/medium throughput experiments. Interestingly, a custom-built, noncommercial nanocalorimeter in a 96-detector array format has been developed and validated for screening applications (Recht et al., 2008; Recht et al.,2016). Compared with conventional calorimeters, its lower volume (500 $\mathrm{nl}$ ) and measure time (5-10 min) are partially offset by a lower sensitivity that narrows the range of equilibrium and rate constant experimentally accessible. See also: DOI: 10.1002/9780470015902.a0003010.pub3; DOI: 10.1002/9780470015902.a0027015.

\section{Thermodynamic Characterization of Molecular Interactions}

\section{Principles}

One of the oldest field of ITC application is the thermodynamic characterization of binding events. The strength of the interaction for a reversible association equilibrium between two molecules, $M$ and $L$, that react to form the complex $M L$ is described by the equilibrium association constant, $K_{a}$,

$$
K_{\mathrm{a}}=\frac{[M L]}{[M][L]}=\frac{1}{K_{d}}
$$

where $[\mathrm{ML}]$ is the concentration of complex, and $[\mathrm{M}]$ and $[\mathrm{L}]$ the concentrations of unbound reactants, and $K_{\mathrm{d}}$ de dissociation constant. Eqn. [2] relates $K_{\mathrm{a}}$ with the Gibbs free energy of binding $(\Delta G)$, that can be expressed in terms of the enthalpic $\Delta H$ and entropic $\Delta S$ contributions to the binding affinity ( $R$ is the universal gas constant and $T$ the absolute temperature in Kelvin): 
In biological terms, L could be a drug, cofactor, inhibitor, metal ion, polypeptide, oligonucleotide, protein, oligonucleotide, carbohydrate or any other molecule that noncovalently interact with a specific site of a second molecule (usually, but not necessarily a protein, nucleic acid, lipid, polysaccharide or nanoparticle). See also: DOI: 10.1002/9780470015902.a0003010.pub3; DOI: 10.1002/9780470015902.a0001341.pu b3.

\section{Titration protocols}

Typically, titration experiments are carried out by stepwise addition of the reagent in the syringe ( $L$ ) into the reaction cell containing the other reactant (M). Each injection triggers the binding reaction and the heat flow is proportional to the thermal power. The area under each peak corresponds to the heat measured at the injection, $Q_{\mathrm{i}}$, given by Eqn. [3],

where $\mathrm{V}$ is the cell volume and $\Delta[\mathrm{ML}]_{i+\mathrm{I}}$ the increment in complex concentration between consecutive injections. As full conversion of $M$ into $M L$ is approached, the size of the peaks decreases until only the amount of heat associated with other effects (ligand dilution, liquid friction, etc.) is observed, yielding the characteristic profile of titration experiments. Blank contribution should be measured by titrating $L$ into buffer in the sample cell, or estimated from the late injections when full complex formation takes place before the end of titration. Some fitting programs can subtract a constant value to detract blank contribution although such option may reduce fitting parameter precision (Tellinghuissen, 2016). It is advisable to verify that the dilution heat of $M$ is negligible by recording the heat of buffer injection into the cell loaded with $M$, and otherwise subtract its contribution from the experimental values. The instrument software integrates the area under each injection peak, subtracts the heat of blanks, if required, and produces the isotherm of binding shown in Figure 1b (bottom), where the heat evolved in each injection, normalized per mole of $L$ injected, is plotted as a function of the molar ratio $[\mathrm{L}] \mathrm{T} /[\mathrm{M}] \mathrm{T}$ (quotient between the total concentration of $\mathrm{L}$ and $\mathrm{M}$ in the cell). Using nonlinear squares algorithms, the analysis software fits the integrated data to the appropriate binding equation to yield the best fitting values and probable errors for $K_{a}$ (and then $\Delta \mathrm{G}$ ), $\Delta \mathrm{H}, \Delta \mathrm{S}$ and the stoichiometry of binding $(n)$. Figure $\mathbf{1 b}$ also indicates the thermodynamic properties yielded by different parts of the curve.

A continuous single-injection titration method (SIM), applicable to very rapid binding reactions, has been developed as an alternative to the incremental titration method (Markova and Hallén, 2004). In this procedure, particularly indicated at low $\Delta H$ values, only one slow, continuous injection of $L$ is made from the syringe into the sample cell filled with $M$, as shown in Figure 1c. Using the instrument software, the raw thermogram (top plot) is filtered and corrected for the response time $(\tau)$ of the instrument and blank/s effects, the concentration continuous calculated, and the conventional plot of the normalized heat $v s[\mathrm{~L}]_{\mathrm{T}} /[\mathrm{M}]_{\mathrm{T}}$ generated (Figure 1c, bottom). 
The experiment can be completed in less total time than required for incremental titrations but the accuracy of the binding parameters obtained from well-designed multiple-injection experiments is usually higher. Nonetheless, the higher density of data points obtained from SIM titration can facilitate discrimination between different binding models.

Usually, when one of the reactant is a macromolecule and the other a small ligand, the macromolecule is loaded in the sample cell and the small ligand in the injection syringe, but this setting can be inverted, depending on the stability, availability and solubility of the reactants, and the nature of the event to be studied.

At present, only ITC allows a complete thermodynamic characterization of binding reactions in a single experiment. By performing measurements at different temperatures, the heat capacity change $\left(\Delta \mathrm{C}_{\mathrm{p}}=(\delta \Delta \mathrm{H} / \delta \mathrm{T})_{P}\right)$ associated with the binding reaction can also be obtained from the slope of the plot of $\Delta \mathrm{H} v s$. T. By contrast, determination of the binding parameters by other techniques requires measuring $K_{a}$ at different temperatures in order to get $\Delta \mathrm{H}$ by means of the van't Hoff equation (Eqn. [4]), and then $\Delta S$ (Eqn. [2]).

$$
\frac{d \ln K_{a}}{d(1 / T)}=-\frac{\Delta H_{v H}}{R}
$$

Using buffers with different ionization enthalpies, $\Delta H_{i o n}$, allows to assess if ligand binding is linked to proton exchange, since the observed $\Delta \mathrm{H}$ will linearly depend on $\Delta \mathrm{H}_{\text {ion }}$ (Gómez and Freire 1995). See also: DOI: 10.1002/9780470015902.a0003010.pub3. DOI: $10.1038 /$ npg.els.0003117.

\section{Selection of reagent concentrations}

Successful design of titration experiments should accomplish the following requirements: i) initial reactant concentrations must guarantee completion of the reaction at the end of titration, and ii) heat change should be within the calorimeter detection range. For oneto-one complexes or when $M$ has a single set of identical sites, the shape of the titration curve is determined by a dimensionless parameter, $c$, defined as the product of $K_{a}$ for the total concentration of sites in the sample cell $\left(c=K_{\mathrm{a}} \cdot[\mathrm{M}]_{\mathrm{T}} \cdot n\right.$; Wiseman et al., 1989). At very high $c$ values the binding isotherm loses its characteristic curvature and the slope tents towards verticality (Figure 2a), making estimation of $K_{a}$, but not of $\Delta H$, unreliable. Conversely, at very low $c$ values the isotherm appears as featureless which would make $K_{\mathrm{a}}$ and $\Delta \mathrm{H}$ determination unreliable (see below). Accurate estimation of $K_{\mathrm{a}}$ apparently requires $1 \leq c \leq 1000$, the ideal range being $10 \leq c \leq 100$ (Figure 2a). In practice this impose upper $\left(10^{8}-10^{9} \mathrm{M}^{-1}\right)$ and lower $\left(10^{3}-10^{4} \mathrm{M}^{-1}\right)$ limits to $K_{\mathrm{a}}$ values directly appraisable by ITC.

On the other hand, measuring $\Delta \mathrm{H}, K_{\mathrm{a}}$ and $n$ by deconvolution of titration data requires at least 10 separate injections to define the binding isotherm, and each injection heat must be, on average, 10 times the limit of detection to be precisely detected. So, the minimal total heat, $Q_{t}$, to be measured for a low volume ITC with a detection limit of $0.02 \mu \mathrm{cal}$ (see above) is $2 \mu \mathrm{cal}$; i.e. 


$$
Q_{\mathrm{t}}=2 \cdot 10^{-6} \mathrm{cal}=n \cdot \Delta H \cdot \mathrm{V} \cdot[\mathrm{M}]_{\mathrm{T}}=n \cdot \Delta \mathrm{H} \cdot[\mathrm{M}]_{\mathrm{T}}\left(0.2 \cdot 10^{-3} \mathrm{~L}\right)
$$

For a $1: 1$ complex $(n=1)$ with a $\Delta \mathrm{H}$ of $-10 \mathrm{kcal} / \mathrm{mol}$, solving Eqn. [5] for [M]T gives a minimum concentration of ca. $1 \mu \mathrm{M}$. This concentration will be in the experimental window for $K_{\mathrm{a}} \geq 10^{6} \mathrm{M}^{-1}$. At lower $K_{\mathrm{a}}$ values, $\mathrm{M}_{\mathrm{T}}$ should be increased so that $1 \leq[\mathrm{M}]_{\mathrm{T}} \cdot K_{\mathrm{a}}$ $\leq 10^{3}$. For high volume instruments as the VP-ITC the minimal concentration is rather similar since the lower sensitivity of the instrument is almost compensate by the higher cell volume. In general, minimal $\mathrm{M}_{\mathrm{T}}$ is determined by the instrument sensitivity for highaffinity ligands, and by the accessible $K_{a}$ window for medium-affinity ligands. Nonetheless, better appraisals of thermodynamic parameters are achieved using higher $M_{T}$ concentrations (heat signal will be larger, and $c$ will approach the ideal 10-102 range). In such conditions, saturation of $\mathrm{M}$ can be almost achieved at a final molar ratio of c.a. 2.

Poor solubility of receptors and ligands is a common problem in ITC, more often when dealing with low affinity systems, which requires working at low $c$ values. Figure $\mathbf{2 a}$ is commonly accepted as evidence for the failure of isotherm fitting al low $c$ values, since the curve becomes an almost flat line with no distinctive features. However, this is only true for the interval of molar ratios displayed in the figure, which is insufficient to describe $90 \%$ of whole isotherm when $c<1$. In such conditions, the saturation degree depends on $K_{\text {a }}$ rather than on $\mathrm{M}_{\mathrm{T}}$. As a rule of thumb, free $L$ concentration in cell must be $\left(10 \cdot K_{d}\right)$ to reach $90 \%$ saturation and $\left(100 \cdot K_{d}\right)$ for $99 \%$ saturation for non-cooperative binding. So, $K_{a}$ and $(n \cdot \Delta \mathrm{H})$ can be accurately derived from titrations at low $c$ values when: $i$ ) a sufficient part of the binding isotherm is monitored, $i i)$ there is an adequate level of signal-to-noise in the data, and iii) the concentrations of $L$ and $M$ are accurately known. Additionally, the use of variable volumes (small at first and larger as the injection number increases) can yield a better distribution of heat, and so a better parameter precision (Figure $\mathbf{2 b}$ ). The strong correlation existing between $n$ and $\Delta \mathrm{H}$ at $c<1$, prevents a reliable determination of both parameters unless $n$ is known by an independent appraisal (Turnbull and Daranas, 2003; Tellinghuisen 2016).

Experiment design for non-equivalent multi-site systems and other complex binding models is often a difficult task, the $c$ parameter being meaningless for them. New tools have been implemented in different software to help select the best titration settings and the reagent concentrations in cell and syringe by simulation of ITC experiments. See also: DOI: 10.1002/9780470015902.a0003010.pub3.

\section{Measuring the affinity of tight- and weak-binding ligands}

Evaluation of tight binding can be carried out by competition with a weaker affinity ligand previously pre-bound to $\mathrm{M}$ (Sirgurskjold, 2000). In the conventional approach the binding parameters of the weakest ligand and $\Delta H$ of the high-affinity ligand are determined in separated experiments (Figure 2c). Ideally, concentration of the competing ligand $[\mathrm{B}] \mathrm{T}$ should be selected so that $K_{\mathrm{a}} /\left(K_{\mathrm{B}} \cdot[\mathrm{B}] \mathrm{T}\right) \cong 10^{5}-10^{8} \mathrm{M}^{-1}$, $K_{\mathrm{a}}$ being the tight-ligand constant. Alternatively, simultaneous characterization of the binding of a high-affinity and a moderate-affinity ligand for the same receptor can be achieved either by $i$ ) titration of the tight-binding ligand into a solution containing the moderate-affinity ligand and the receptor present in excess (Figure 2d; Krainer and Keller, 2015), or ii) 
titration of the receptor into a dilute mixture of the two competing ligands to overcome limitations imposed by poorly water-soluble compounds (Figure 2e; Krainer et al., 2012). When a suitable competing ligand is available, the displacement protocol can also be applied to low affinity ligand characterization, by measuring the binding parameters of a good ligand in the absence and presence of the low affinity ligand (Zhang and Zhang, 1998; Velázquez-Campoy et al., 2004). The possibility of using a competitor with $\Delta H$ opposite to the high- or low-affinity ligand has the added benefit of amplifying the calorimetric signal during the displacement experiments (Velazquez-Campoy et al., 2001).

Competition protocols extent the $K_{a}$ window to $10^{2}-10^{12} \mathrm{M}^{-1}$ and are particularly useful in supramolecular chemistry and in drug design, where the ability to accurately measure binding affinities in the sub-nanomolar range is essential (Velázquez-Campoy et al., 2001). Affinities in the millimolar range are also critical during lead optimization stage, as high-affinity ligands can be constructed by tethering together complementary low affinity fragments (Fattori, 2004; Retch et al., 2016), and many biological processes are mediated by low affinity interactions (e.g. carbohydrate-protein; carbohydratecarbohydrate, cyclodextrin-guest).

\section{Analysis of binding isotherms}

The use of ITC in binding thermodynamic studies is now well established and there are excellent reviews in which a wide number of applications is provided and the thermodynamics behind the studied processes scrutinized. A selection of papers illustrating ITC applications in biology, supramolecular chemistry and natural products is gathered in Table 2. Models to fit or simulate ITC binding data available in the software provided by ITC manufactures (Origin and NanoAnalyse) include the one-site model, the two set of independent sites, sequential filling of binding sites, dimer dissociation, and the competition-binding model, and user-made models have been developed to analyze more complex processes (Velázquez-Campoy 2015). Several other packages including simulation and global fit of titration curves to a variety of binding models (SEDPHAT, AFFINImeter, pytc), or user-unbiased integration of data sets (NITPIC, AFFINImeter, pytc) have been developed. AFFINImeter and pytc also allow easy implementation of new fitting models, whereas SEDPHAT and AFFINimeter provide the species population along the whole titration (see Table 1).

Interpretation of binding isotherms in simple molecular terms is not always easy. Even for multi-sites systems the number of binding parameters can quickly exceed what can be confidently determined from a single data set or titration configuration. Therefore, global analysis of different experiments - at identical or varying conditions to provide a single set of binding parameters is an efficient way of improving the reliability of fits, by reducing the number of freedom degrees in the fitting model (Zhao et al., 2015; Muñoz \& Piñeiro, 2018). Its use becomes increasingly important as the system complexity increases, as characterization of multi-component systems usually requires multiple titration experiments in different configurations. In such scenario, simultaneous and direct fitting of all data sets is often more accurate and stringent than the analysis with apparent binding constants extracted from independent analysis, and helps to elucidate complex binding mechanisms, as illustrated in Figure 3a-d. See also: DOI: 10.1002/9780470015902.a0003010.pub3;

DOI: 
10.1002/9780470015902.a0027015; DOI: 10.1002/9780470015902.a0001341.pub3; DOI: $10.1002 / 9780470015902 . a 0001340 . p u b 2$;

\section{Thermodynamic binding signature}

As it can be inferred from Eqn. [2], $\Delta \mathrm{H}$ and $\Delta \mathrm{S}$ determine the binding affinity. $\Delta \mathrm{H}$ primarily reflects the strength of the interactions responsible for complex formation (e.g. hydrogen bonds, van der Waals interactions, etc.) relative to those existing with the solvent, whereas the entropy change mainly reflects variations in the solvation entropy (particularly important for hydrophobic groups) and in conformational entropy (lose of conformational freedom upon complex formation). $\Delta C_{p}$ of binding primarily reflects the burial of polar and non-polar surfaces due to the binding reaction (Gomez et al., 1995; Schön and Freire, 2016). As a result, different types of interactions reflect themselves in different thermodynamic signatures (entropy and enthalpy changes; Figure 4), and two ligands that have different $\Delta \mathrm{H}$ and $\mathrm{T} \Delta \mathrm{S}$ contributions will have different mechanism of binding, even if their binding affinities may be the same (Velázquez-Campoy et al., 2004). $\Delta H$ and $\Delta S$ have been, therefore, acknowledged as critical determinants of important drug properties (Velázquez Campoy et al., 2001; Klebe, 2015;); only intrinsic parameters of binding can be used in structure-activity relationship in drug development of mechanistic studies of modes of binding. See also: DOI: 10.1002/9780470015902.a0003011.pub2; DOI: 10.1002/9780470015902.a0002974.pub2.

\section{Evaluation of Kinetic Constants from ITC Titration Experiments}

Kinetic information on binding events is central to understand biological processes in vivo. However, little attention has been paid to this aspect until very recently. Since the heat produced or absorbed during each ligand injection - due to a small sequential perturbation of the equilibrium under study - is monitored as a function of time, titration raw data contain intrinsic kinetic information of the binding process. Nonetheless, ITC experiments have generally been designed to obtain only thermodynamic information. The availability of highly sensitive instruments with low response time ( 3.5 to $10-12 \mathrm{~s}$ ), together with the development of theoretical methods and public software (kinITC) to analyse the shape of the ITC peaks, have drastically reduced the barriers for retrieving kinetic data ( $k_{\text {on }}$ and $k_{\text {off; }} K_{\mathrm{a}}=k_{\mathrm{on}} / k_{\text {off }}$ ) from bimolecular reactions ( $\mathrm{M}+\mathrm{L} \leftrightarrows \mathrm{ML}$ ), even if they proceed through complex mechanisms (Burnouf et al., 2012, Vander Meulen et al., 2016). Recently, a methodological simplification (kinITC-ETC) applicable to one-step bimolecular processes has been implemented in the AFFINIMETER software (Dumas et al., 2016; Muñoz et al., 2019). Together with affinity data, kinITC-ETC determines $k_{\text {on }}$ and $k_{\text {off }}$ by measuring the time required to return to equilibrium at each injection as a function of $[\mathrm{L}] \mathrm{T} /[\mathrm{M}] \mathrm{T}$ ratio (Figure 5a-d). By doing titrations at several temperatures, $\Delta C_{\mathrm{p}}$, the van't Hoff enthalpy and entropy, and the enthalpy and entropy of activation $\left(\Delta \mathrm{H}^{\ddagger}\right.$ and $\left.\Delta \mathrm{S}^{\ddagger}\right)$ can be derived as well. Of note, kinetic results will be correct only if the kinetic model used was correct. Besides, thorough cleaning of the instrument is essential to obtain reliable results as the $\tau$ value of the instrument strongly depends on the cleanness of the sample cell (Dumas et al., 2016). Kinetic analysis of ITC data using 
kinITC or kinITC-ETC compared to those performed with other biophysical techniques have been reported for a variety of systems, covering from simple ligand binding to folding processes triggered by ligand binding (Burnoud et al., 2012; Van der Meulen and Butcher 2012; Dumas et al.,2016; Muñoz and Piñeiro 2018). Noteworthy, the study of bacterial adhesin FimH binding to a collection of antagonists with a broad range of affinities highlighted how combination of thermodynamic and kinetic information helps to derive structural information on the mode of binding (Zihlmann et al., 2018).

\section{Enzyme Kinetic Characterization}

ITC can be used to monitor the progression of enzyme catalyzed reactions and is emerging as a powerful tool for measuring the kinetics of challenging enzymes and precise conditions for specific enzyme activity (Sotoft et al., 2010; Murphy et al., 2010). In comparison with conventional methods, ITC allows using physiological and synthetic substrates, immobilised enzymes, or media that mimic physiological conditions, is as rapid and sensitive as spectroscopic techniques but do not require additional reagents, tags or secondary reactions (Reimund et al., 2017). Enzyme activity can be titrated in two different ways: $i$ ) by successive injections of substrate, $\mathrm{S}$, into the enzyme solution, allowing the baseline to equilibrate between injections (Figure 1d), and ii) by a single injection of $\mathrm{S}$ into the cell loaded with enzyme, $\mathrm{E}$, (or viceversa), monitoring the signal change until all the substrate has reacted (Figure 1e).

The amount of heat, $Q$, associated with conversion of $m$ moles of substrate $S$ in product $P$ after triggering the reaction by $S$ injection is given by:

$$
Q=m \cdot \Delta \mathrm{H}_{\mathrm{app}}=[\mathrm{P}] \cdot \mathrm{V} \cdot \Delta \mathrm{H}_{\mathrm{app}}
$$

where $\Delta \mathrm{H}_{\text {app }}$ is the molar enthalpy of product formation. Hence, the experimental signal $(d Q / d t)$ generated by the enzymatic reaction allows to know the reaction rate, $v$, defined as the variation of product concentration with time $d[P] / d t$.

$$
v=\frac{d[P]}{d t}=\frac{1}{V \cdot \Delta H_{a p p}} \cdot \frac{d Q}{d t}
$$

In the multiple injection method, the shift in the power signal after injection $i,\left(d Q_{i}\right.$ $/ \mathrm{d} t$ ), is proportional to the substrate concentration [S] in the cell, and subsequent injections take place when the signal has reached a steady state and prior to significant reaction of S (Figure $\mathbf{6 a}$ ). The difference between the original baseline and the plateau attained after each injection is used to create a plot of the reaction rate vs [S] (Figure 6b). $\Delta \mathrm{H}_{\text {app, }}$ required for conversion of experimental rates (power units) to enzyme turnover, is determined in an independent experiment at higher enzyme concentration by allowing complete substrate depletion and then integrating the total heat evolved (Figure 6c):

$$
\Delta \mathrm{H}_{\mathrm{app}}=\frac{1}{V \cdot[S]_{\text {total }}} \int_{t=0}^{t=\infty} \frac{d Q(t)}{d t} d t
$$


As rates are measured at steady-state conditions, they do not depend on $\tau$ and the fit of the kinetic curves to standard equations would yield $k_{\text {cat }}$ and $K_{\mathrm{m}}$. This method can be used when $K_{\mathrm{m}}>10 \mu \mathrm{M}$ and $[\mathrm{E}]<<[\mathrm{S}]_{\mathrm{T}}$.

In the single injection method, a continuous kinetic curve is generated by monitoring the thermal power as $\mathrm{S}$ is completely transformed (Figure 1e) and $\Delta \mathrm{H}_{\text {app }}$ is calculated by integrating the total heat. At any given time, $v$ can be calculated from the thermal power using Eqn. [7], and the remaining substrate concentration [S](t) from the integral of the heat evolved (Eqn. [9]).

$$
[\underline{\mathrm{S}}]_{(\mathrm{t})}=[\mathrm{S}]_{\mathrm{T}}-[\mathrm{P}]_{(\mathrm{t})}=[\mathrm{S}]_{\mathrm{total}}-\frac{\int_{t=0}^{t} Q_{(t)}}{V \cdot \Delta H_{a p p}}
$$

The impact of $\tau$ in the analysis of single injection data will be marginal if $K_{\mathrm{m}}<10 \mu \mathrm{M}$ and $[\mathrm{S}]>>K_{\mathrm{m}}$ (Todd and Gomez, 2001). At higher values of $K_{\mathrm{m}}$ or when $[\mathrm{S}]<<K_{\mathrm{m}}$ the effect may be minimized by choosing experimental conditions where $0.1 / \tau<\left(k_{\text {cat }} \times[E] / K_{m}\right)<$ $1 / \tau$ and the reaction goes at least to $99 \%$ completion. Otherwise, raw data have to be mathematically corrected to remove the effect of the finite response time of the instrument on $k_{\text {cat }}$ and $K_{m}$ calculation (Transtrum et al., 2015).

The analysis of kinetic essays performed with and without competitive inhibitors is implemented in the software provided by ITC manufacturers, as well as calculation of $K_{\mathrm{m}}, K_{\text {cat }}$ and $K_{\mathrm{i}}$ (inhibition constant) for Michaelis-Menten kinetics. The $\tau$ value provided with the instrument is used for single-injection data correction. However, $\tau$ can vary with the experimental conditions (e.g. density of solutions), and the protocol and equations required to include $\tau$ as a fitting parameter for the Michaelis-Menten model have been reported (Hansen et al., 2011; Demarse et al., 2013).

Under appropriate conditions both methods provide a precise characterization of enzyme kinetics (Todd and Gomez 2001; Transtrum et al., 2015; Hansen et al., 2016), including fast evaluation of inhibitor/activators capacities and the investigation of their mechanism of action. Indeed, ITC is extremely powerful to characterize enzyme inhibitors, a central theme, for example, to lead generation and optimization in drug development (Recht et al., 2016). Remarkably, a simple and effective ITC assay, built on sequential singleinjections with substrate and inhibitor premixed in the injection syringe, has been recently developed to completely characterize enzyme inhibition in a single experiment (Di Trani et al., 2018). Product inhibition, hard to evaluate in simple spectrophotometric assays, can be easily detected by ITC (Draczkowski et al., 2016). As in the thermodynamic studies, the use of buffers with different $\Delta \mathrm{H}_{\text {ion }}$ allows to evaluate the net exchange of protons during catalysis (Todd and Gomez; 2001; Draczkowski et al., 2016). See also: DOI: 10.1002/9780470015902.a0000716; DOI: 10.1002/978047 0015902.a0000714.pub2; DOI: 10.1002/978047 0015902.a0000719.pub2; DOI: 10.1002/9780470015902.a0000865.pub3; DOI: 10.1038/npg.els.0000862; DOI: $10.1038 /$ npg.els. 0000600 .

\section{Experimental Remarks}


1 - A clean cell and a perfectly straight syringe are decisive to avoid false results and to 2 get excellent baselines with high signal-to-noise ratio.

3 - Incertitude in $K_{a}, \Delta \mathrm{H}$ and $n$ relies in accurate determination of reactant concentrations.

4 - Concentrations of reactants should guarantee reaching the saturation point in a 5 reasonable number of injections.

6 - Both reactants have to be in identical solutions. Even small buffer mismatches can 7 generate large dilution heats, which can mask the heat of ligand binding. Extreme care 8 should be taken when using DMSO, glycerol, detergents or high salt concentrations.

9 - Use buffers in which ligand and macromolecule are stable and soluble. Be sure that 10 buffer concentration can compensate for any $\mathrm{pH}$ effects during titration. - Before ITC, dialyze reactants against the same dialysis buffer. Use the final dialysis buffer to solubilize small-ligands. Glycerol and detergents dialyze slowly and its use requires longer dialysis time.

- If DMSO is needed to solve a ligand, check ligand solubility by serial dilutions of $100 \%$ DMSO stock solution in buffer. Immediately before the experiment, add DMSO to the protein solution (many proteins are stable, in the short term, in up to 2-5\% DMSO).

- Use TCEP or beta-mercaptoethanol rather than DTT if a reducing agent is needed. DTT can produce aberrant baselines.

- Baseline assignment is of capital importance for precision of experimental data and of derived parameters. Bias-free automated assignment of baselines and inclusion of peak integration-associated errors in fitting is recommended.

- If the heat of blanks varies perceptibly with the injection number, reaction heats should be corrected peak by peak, subtracting the blank integrated curve (or a function fitting blank heats) from the titration one.

- Experimental data should be analyzed using the simplest model that makes sense with prior knowledge of the system (e.g. stoichiometry).

- Errors provided by fitting methods reflect only the goodness of fit of a model to a particular set of results. Estimate of random error must be obtained from measurement repetition.

\section{References:}

Baranauskiene L, Kuo T-C, Chen W-Y and Matulis D (2019) Isotermal titration calorimetry for characterization of recombinant proteins. Current Opinion in Biotechnology 55: 9-15.

Brautigam CA, Zhao H, Vargas C, Keller S and Schuck P (2016) Integration and global analsis of isothermal titration calorimetry data for studying macromolecular interactions (NitPic). Nature Protocols 11: 882-894.

Burnouf D, Ennifar E, Guedich S, Puffer B, Hoffman G, Bec G, Disdier F, Baltzinger M and Dumas P (2012) kinITC: A new method for obtaining joint thermodynamic and 
kinetic data by isothermal titration calorimetry. Journal of the American Chemical Society 134: 559-565.

Burrows SD, Doyle ML, Murphy KP, White FJR, Brooks I, McNulty DE, Scott MO, Knutson JR, Porter D, Young PR and Hensley P (1994). Determination of monomer-dimer equilibrium of interleukin-8 reveals it is a monomer at physiological concentration. Biochemistry 33: 12741-12745.

Buurma NJ and Haq I (2007) Advances in the analysis of isothermal calorimetry data for ligand-DNA interactions. Methods 42: 162-172.

Callies O and Hernández Daranas A (2016) Application of isothermal titration calorimetry as a tool to study natural product interactions. Natural Product Reports 33: 881-904.

Demarse NA, Killian MC, Hansen LD and Quinn CF (2013) Determining enzyme kinetics via isothermal titration calorimetry. Methods in Molecular Biology 978:32-52.

Di Trani JM, Moitessier N and Mittermaier AK (2018). Complete kinetic characterization of enzyme inhibition in a single isothermal titration calorimetric experiment. Analytical Chemistry 90: 8430-8435.

Drazckowski P, Tomaszuk A, Halczuk P, Strzemski M, Matosiuk D and Jozwiak K (2016) Determination of affinity and efficacy of acetylcholinesterase inhibitors using isothermal titration calorimetry. Biochimica et Biophysica Acta 1860: 967-974.

Dumas P, Ennifar E, Da Veiga C, Bec G, Palau W, Di Primo C, Piñeiro A, Sabin H, Muñoz E and Rial H (2016) Extending ITC to kinetics with kinITC. Methods in Enzymology 567: 157-180.

Duvvuri H, Wheeler LC and Harms MJ (2018) pytc: Open-source Python software for global analysis of isothermal titration calorimetry data. Biochemistry 57: 2578-2583.

Fattori D (2004) Molecular recognition: The fragment approach in lead generation. Drug Discovery Today 9: 229-238.

Freyer MW and Lewis EA (2008) Isothermal titration calorimetry: Experimental design, data analysis, and probing macromolecule/ligand binding and kinetic interactions. Methods in Cell Biolology 84: 79-113.

Gómez J and Freire E (1995) Thermodynamic mapping of the inhibitor site of the aspartic protease endothiapepsin. Journal of Molecular Biology 252: 337-350.

Hansen LD, Transtrum MK, Quinn C and Demarse N (2016) Enzyme-catalyzed and binding reaction kinetics determined by isothermal titration calorimetry. Biochimica et Biophysica Acta 1860: 957-966.

Houtman JCD, Brown PH, Bowden B, Yamaguchi H, Appella E, Samelson LE and Schuck P (2007) Studying multisite binary and ternary protein interactions by global analysis of isotheral titration calorimetry data in SEDDPHAT: Application to adaptor protein complexes in cell signaing. Protein Science 16: 30-42.

Huan R and Lau BLT (2016) Biomolecule-nanoparticle interactions: Elucidation of thermodynamics by isothermal titration calorimetry. Biochimica et Biophysica Acta 1860: 945-956. 
Ikeda M, Takeda M and Yoshioka T (2013) Thermal dynamics of metabotropic glutamate receptor signaling revealed by subtraction micro-calorimetric measurements on live cells. Protocol Exchange. DOI: 10.1038/protex.2013.061.

Keller S, Vargas C, Zhao H, Piszczek G, Brautigam Ah A and Schuck P (2012) Highprecision isothermal titration calorimetry automated peak-shape analysis. Analytical Chemistry 84: 5066-5073.

Klebe G (2015) Applying thermodynamic profiling in lead finding and optimization. Nature Reviews in Drug Discovery 14: 95-110.

Krainer G, Broecker J, Vargas C, Fanghänel J and Keller S. (2012) Quantifying highaffinity binding of hydrophobic ligands by isothermal titration calorimetry. Analytical Chemistry 84: 10715-10722.

Krainer G and Keller S. (2015) Single-experiment displacement assay for quantifying high-affinity binding by isothermal titration calorimetry. Methods. 76: 116-123.

Kumar GS and Basu A (2016) The use of calorimetry in the biophysical characterization of small molecule alkaloids binding to RNA structures. Biochimica et Biophysica Acta 1860: 930-944.

Linkuviene V, Zubriené A, Manakova E, Petrauskas V, Baranauskinè L, Zakšauskas A, Smirnov A, Grazulis S, Ladbury JE and Matulis D (2018) Quaterly Reviews of Biophysics 51: e10, 1-48.

Loh W, Brinatti C and Tam KC (2016) Use of isothermal titration calorimetry to study surfactant aggregation in colloid systems. Biochimica et Biophysica Acta 1860: 999-1016.

López-Morales CA, Miranda-Hernández MP, Juárez-Bayardo LC, Ramírez-Ibáñex NC, Romero-Dçiaz AJ, Flores-Ortiz LF and Medina-Rivero E (2015) Physichochemical and biological characterization of a biosimilar tastuzumab. BioMed Research International, Article ID 427235.

Marchetti R, Malinovska L, Lameignère $E$, Adamova L, de Castro C, Cioci G, Stanetty Ch, Kosma P, Molinaro A, Wimmerova M, Imberty A and Silipo A (2012) Burkholderia cenocepacia lectin A binding to heptoses from the bacterial lipopolysaccharide. Glycobiology 22: 1378-1398.

Markova N and Hallén D (2004) The development of a continuous isothermal titration calorimetric method for equilibrium studies. Analytical Biochemistry 331: 77-88.

Martins PT, Velázquez-Campoy A, Vaz WLC, Cardoso R M S, Valério J and Moreno MJ (2012) Kinetics and Thermodynamics of Chlorpromazine Interaction with Lipid Bilayers: Effect of Charge and Cholesterol. Journal of American Chemical Society 134: 4184-4195.

Muñoz E and Piñeiro A (2018) AFFINImeter software: from its beginning to future trends. Journal of Applied Bioanalysis 4: 124-139.

Muñoz E, Sabín J, Rial J, Pérez D, Esnifar E, Dumas P and Piñeiro A (2019) Thermodynamic and kinetic analysis of isothermal calorimetry experiments by using kinITC in AFFINImeter. Microcalorimetry of Biological Molecules: Methods and Protocols, Methods in Molecular Biology 1964: 225-239. 
Murphy L, Borch K, McFarland KC, Bohlin C and Westh P. (2010) A calorimetric assay for enzymatic saccharification of biomass. Enzyme and Microbial Technology 46: 141-146.

Piñeiro A, Muñoz E, Sabín J, Costas M, Bastos M, Velázquez-Campoy, Garrido PF, Dumas P, Ennifar E, García-Rio L, Rial J, Pére D, Fraga P, Rodríguez A and Cotelo C (2019) AFFINImeter: A software to analyze molecular recognition processes from experimental data. Analytical Biochemistry 577: 117-134.

Quinn CF, Carpener MC, Croteau ML and Wilcox DE (2016) Isothermal titration calorimetry measurements of metal ions binding to proteins. Methods in Enzymology 567: 3-21.

Rajrathnam K and Rösgen J (2014) Isothermal titration calorimetry of membrane proteins - Progress and challenges. Biochimica et Biophysica Acta 1838: 69-77.

Rajasekar KV, Zdanowski K, Yan J, Hopper JTS, Rancis M-LR, Seepersad C, Sharp C, Pecquer L, Werner JM, Robinson CV, Mohammed S, Potts JR and Kleanthous C (2016) The anti-sigma factor RsrA responds to oxidative stress by reburying its hydrophobic core. Nature Communications 7:12194. Doi: 10.1038/ncomms 12194.

Recht MI, Bruyker D, Bell AG, Wolkin MV, Peters E, Anderson GB, Kolatkar AR, Bern MW, Kuhn P, Bruce RH and Torres FE (2008) Enthalpy array analysis of enzymatic and binding reactions. Analytical Biochemistry 377: 33-39.

Recht MI, Nienaber $V$ and Torres FE (2016) Fragment-based screening for enzyme inhibitors using calorimetry. Methods in Enzymology 567: 47-69.

Reimund M, Kovrov O, Olivecrona G and Lookene A (2017) Lipoprotein lipase activity and interactions studies in human plasma by isothermal titration calorimetry. Methods 58: 279-288.

Scheuarmann TH and Baritigam CA (2015) High-precision, automated integration of multiple isothermal titration calorimetric thermograms: new features of NITPIC. Methods 76: 87-98.

Schön A and Freire E (2016) Enthalpy screen of drug candidates. Analytical Biochemistry 513: 1-6.

Sigurskjold BW (2000) Exact analysis of competition ligand binding by displacement isothermal titration calorimetry. Analytical Biochemistry 277: 260-266.

Sahu D, Bastidas M, Lawrence ChW, Noid WG and Showalter SA (2016) Assessing coupled protein folding and binding through temperature-dependent isothermal titration calorimetry. Methods in Enzymology 567: 24-45.

Sotoft LF, WesthP, Christensen KV and Norddahl B (2010) Novel investigation of enzymatic biodiesel reaction by isothermal titration calorimetry. Thermochimica Acta 501: 84-90.

Stateva SR, Salas V, Benaim G, Menéndez M, Solís S and Villalobo A (2015) Characterization of phosph-(tyrosine)-mimetic calmodulin mutants. PlosOne 10(4): e0120798.

Tellinghuisen $\mathrm{J}$ (2016) Optimizing isothermal titration calorimetry protocols for the study of 1:1 binding: Keeping it simple. Biochimica et Biophysica Acta 1860: 861-867. 
Todd MJ and Gomez J (2001) Enzyme kinetics determined using calorimetry: A general assay for enzyme activity. Analytical Biochemistry 296: 179 -187.

Transtrum MK, Hansen LD and Quinn C (2015) Enzyme kinetics determined by singleinjection isothermal titration calorimetry. Methods 76: 194-200.

Turnbull WB and Daranas AH (2003) On the value of c: Can low affinity systems be studied by isothermal titration calorimetry?. Journal of the American Chemical Society 125: 14859-14866.

Vander Meulen KA and Butcher SE (2012) Characterization of the kinetic and thermodynamic landscape of RNA folding using a novel application of isothermal titration calorimetry. Nucleic Acids Research 40: 2140-2151.

Vander Meulen KA, Horowitz S, Trievel RC, Butcher SE (2016) Measuring the kinetics of molecular association by isothermal titration calorimetry. Methods in Enzymology 567: 181-213.

Velazquez-Campoy A (2015) Allostery and Cooperative interactions in proteins assessed by isothermal titration microcalorimetry. Biocalorimetry: Foundations and Contemporary Approaches. 223-246. Bastos M (Ed). CRC Press. Boca Ratón.

Velázquez-Campoy A, Leavitt SA and Freire E (2004) Characterization of protein-protein interactions by isothermal titration calorimetry. Methods in Molecular Biology: Protein-Protein Interactions: Methods and Protocols. (H. Fu Ed; Humana Press Inc.) 261: 25-54.

Velázquez-Campoy A, Kiso $Y$ and Freire E (2001) The binding energetics of first- and second-generation HIV-1 protease inhibitors: Implications for drug design. Archives of Biochemistry and Biophysics 390: 169-175.

Wang X, Zheng K, Si Y, Guo X and Yisheng X (2019) Protein-polyelectrolyte interactions: Thermodynamic analysis based on the titration method. Polymers 11, 82, doi: 10.3390/polym11010082.

Wiseman T, Williston S, Brandts JF, Lin LN (1989) Rapid measurement of binding constants and heats of binding using a new titration calorimeter. Analytical Biochemistry 179: 131-135.

Zakharov MN, Bhasin S, Gravison TG, Xue Rm Ulloo J, Vasan RS, Carter B, Wu F, Jasuja R (2015) A multi-step, dynamic allosteric model of testosterone's binding to sex hormone binding globulin. Molecular and Cellular Endodrinology 399: 190-200.

Zhang Y-L, Zhang Z-Y (1998) Low-affinity binding determined by titration calorimetry using high-affinity coupling ligand: A thermodynamic study of ligand binding to protein tyrosine phosphatase 1B. Analytical Biochemistry 261: 139-148.

Zhao H, Piszczek G and Schuck P (2015) SEDPHAT - a platform for global ITC analysis and global multi-method analysis of molecular interactions. Methods 76: 137-148.

Zihlmann P, Silbermann M, Sharpe T, Jiang X, Mehlethaler T, Jakob RP, Rabbani S, Sager CP, Frei P, Pang L, Maier T and Ernst B (2018) KinITC-One method supports both 
thermodynamic and kinetic SARs as exemplified on FimH antagonists. Chemistry $A$ European Journal 24: 13049-13057. 
(a)

(b)

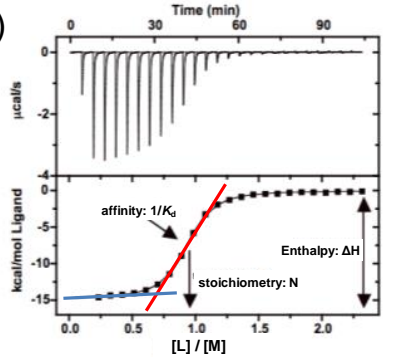

(c) Time (min)
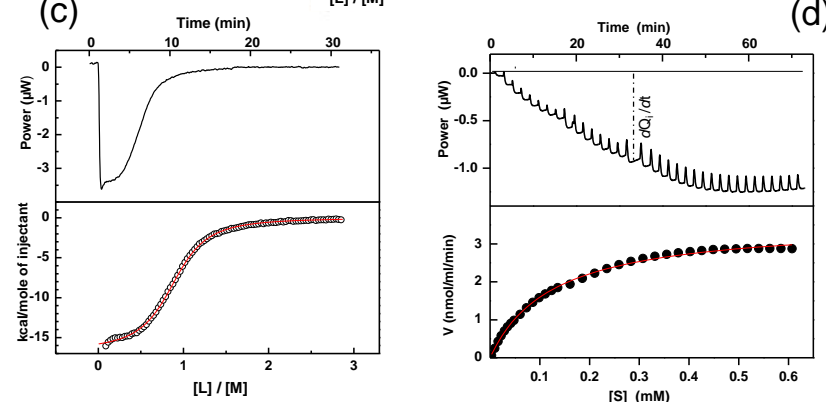

(e)

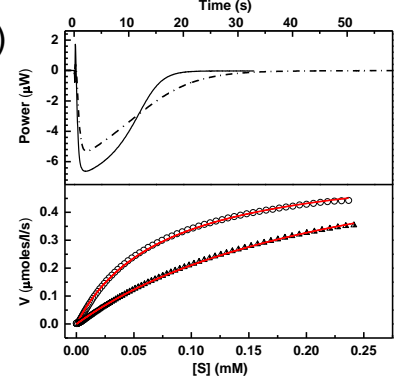

Figure 1. (a) Schematic representation of an ITC instrument based on the dynamic power compensation principle, showing the sample (S) and reference (R) cells enclosed in the thermostated jacket, the injection syringe, and the computer controlled thermostatic, feedback and output systems. (b) Representation of a typical multi-addition experiment (exothermic binding) showing $2^{\prime} \mathrm{CMP}$ titration into RNase $\mathrm{A}\left(25^{\circ} \mathrm{C} ; 20 \mathrm{mM} \mathrm{KAc}, 20 \mathrm{mM} \mathrm{KCl}, \mathrm{pH} 5.0\right.$ ). Raw thermogram (each peak corresponds to one $2^{\prime} \mathrm{CMP}$ injection and peak area represents the heat released at the injection; top plot) and binding isotherm (normalized heat effect per injection vs $\left[2^{\prime} \mathrm{CMP}\right]_{T} /[\text { RNase A }]_{T}$ molar ratio; bottom plot). The solid line through the points is the best fit of results to the one-site model. The amplitude of the curve is proportional to $\Delta \mathrm{H}$, the inflection point gives $n$, and the slope $K_{\mathrm{a}}$. (c) Binding experiment of 2'CMP to RNase A using the SIM method. The experimental signal is shown in the top panel and the continuous plot of normalized heats $v s$ the total molar ratio in the bottom panel $\left(30^{\circ} \mathrm{C}\right.$; buffer as in (b)). The red line is the best fit of results to the one-site model. (d) Representation of a typical ITC enzymatic assay using the multipleinjection method. The thermal power deflection at a given injection $(d \mathrm{Q} \mathrm{i} / d \mathrm{t})$ is proportional to the reaction rate constant and the substrate concentration in the cell (top panel). The rate of product formation as function of [S], calculated from the top plot, is shown the bottom panel. (e) Thermogram of an enzymatic assay using the single-injection method. The thermal power was monitored until complete depletion of the substrate in the absence (solid line) and presence (dashed-dot line) of a competitive inhibitor (top plot), and continuous kinetic curves were generated by plotting the reaction rates measured in the absence (circles) and presence (triangle) of inhibitor vs the remaining concentration of substrate in the cell. Solid red lines in (d) and (e) represent the fit of the kinetic curves to the Michaelis-Menten model. 
(a)

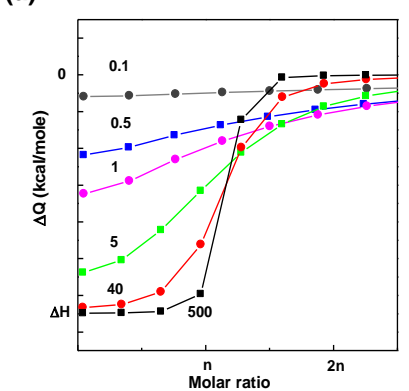

(b)

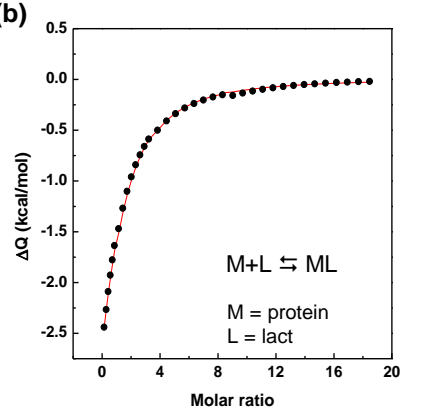

(c)

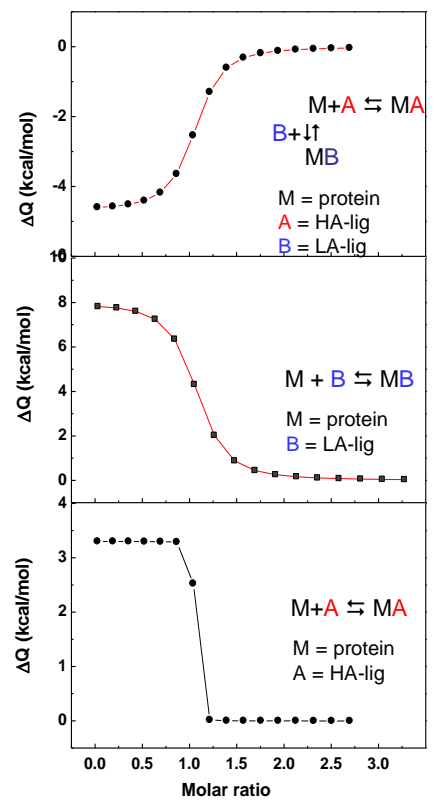

(d)

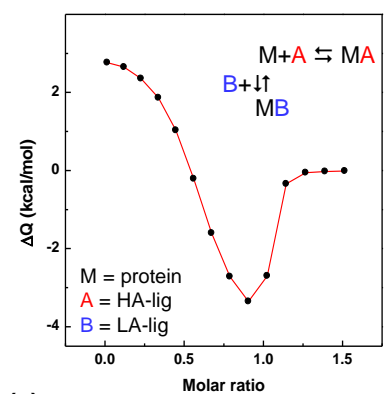

(e)

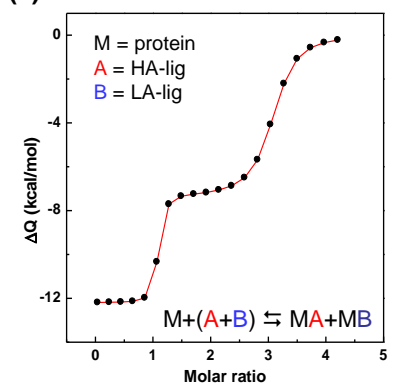

Figure 2. (a) Influence of the " $c$ " value (plot label) on the shape of ITC isotherms for receptors with a single-set of identical sites $(n)$. Simulations were performed assuming $100 \mu M$ of sites and the following $K_{\mathrm{a}}$ values $\left(\mathrm{M}^{-1}\right)$ : grey $\left(10^{3}\right)$; blue $\left(5 \times 10^{3}\right)$; magenta $\left(10^{4}\right)$; green $\left(5 \times 10^{4}\right)$; red $(4 \times$ $\left.10^{5}\right)$ and black $\left(5 \times 10^{6}\right)$. (b) ITC isotherm for titration of lactose (lac; $\left.15 \mathrm{mM}\right)$ into a lectin-like protein (364 $\mu \mathrm{M}$ in cell) at low " $c^{\prime \prime}$ value. Titration was optimized by doing two sequential sets of injections. The red line is the fit of the isotherm with the best parameters (Ka $=1.5 \times 10^{3} \mathrm{M}^{-1}$ and $\Delta \mathrm{H}=-7.06 \mathrm{kcal} / \mathrm{mol}$, fixing $n=1$ ). (c) Simulated isotherms for a three-experiment displacement protocol, showing titration of the high-affinity ligand (HA-lig; $130 \mu \mathrm{M}$ ) into the protein $(\mathrm{M} ; 10 \mu \mathrm{M})$ in the absence (lower plot) and presence (upper plot) of a lower affinity competitor (LA-lig; 200 $\mu \mathrm{M})$, whose titration into $\mathrm{M}$ is shown in the central plot $\left(\mathrm{K}_{\mathrm{HA}-\mathrm{lig}}=2.2 \times 10^{9} \mathrm{M}^{-1} ; \Delta \mathrm{H}_{\mathrm{HA}-\text { lig }}=3.1\right.$ $\left.\mathrm{kcal} / \mathrm{mol} ; \mathrm{K}_{\mathrm{LA}-\mathrm{lig}}=2.3 \times 10^{6} \mathrm{M}^{-1} ; \Delta \mathrm{H}_{\mathrm{LA}-\text { lig }}=8.0 \mathrm{kcal} / \mathrm{mol} ; \mathrm{n}=1\right)$. Red solid lines are the fits of the isotherms. (d) Simulation of a single-experiment displacement titration of HA-lig (130 $\mu \mathrm{M}$ in syringe) into $\mathrm{M}(10 \mu \mathrm{M})$ and LA-lig $(5 \mu \mathrm{M})$ in cell; binding parameters were as in (b). Differences between competition isotherms in upper plot of (c) and (d) are due to full (c) and partial (d) saturation of $M$ sites with LA-lig. (e) Simulation of a competition experiment for complete thermodynamic evaluation of poorly soluble tight ligands by single titration of $M(400 \mu M$ in syringe) into a dilute mixture of $\mathrm{HA}$-lig $(20 \mu \mathrm{M})$ and LA-lig $(7.4 \mu \mathrm{M})$ in cell $\left(\mathrm{K}_{\mathrm{HA}-\mathrm{lig}}=2.2 \times 10^{9} \mathrm{M}^{-1}\right.$; $\left.\Delta \mathrm{H}_{\mathrm{HA} \text {-lig }}=12.2 \mathrm{kcal} / \mathrm{mol} ; \mathrm{K}_{\text {LA-lig }}=2.8 \times 10^{6} \mathrm{M}^{-1} ; \Delta \mathrm{H}_{\text {LA-lig }}=-7.4 \mathrm{kcal} / \mathrm{mol} ; n=1\right)$. 

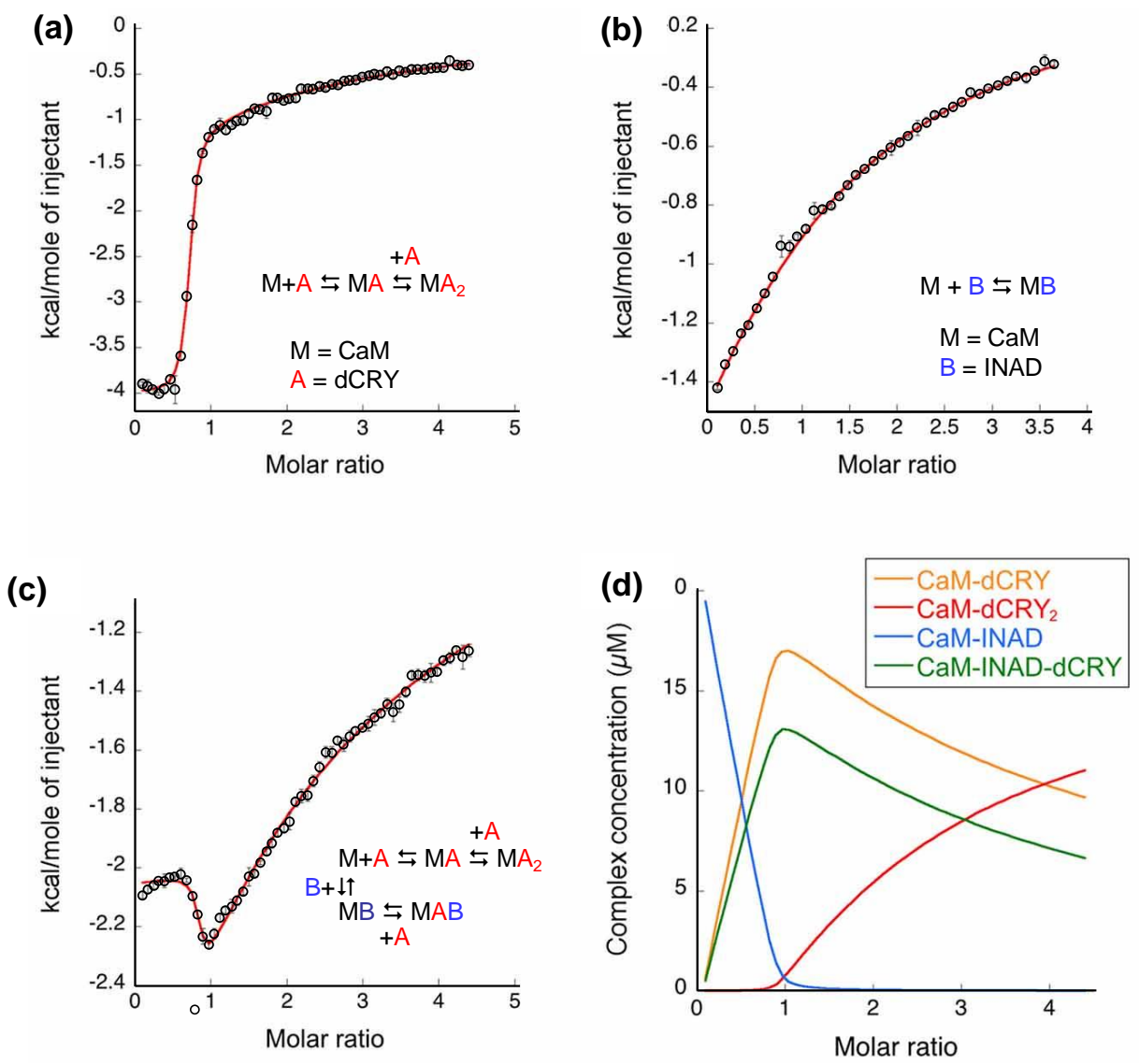

4

Figure 3. Global analysis of ITC isotherms from (a) dCRY (light responsive flavoproteine) titration into $\mathrm{CaM}\left(\mathrm{Ca}^{2+} /\right.$ Calmolulin); (b) INAD (photo-receptor specific protein) titration into $\mathrm{CaM}$; and (c) competitive titration of $\mathrm{dCRY}$ into CaM incubated with INAD. The AFFINImeter models applied to each isotherm in the gobal fitting are indicated in respective panels. (d) Species distribution plot calculated from the competition experiment. Simultaneous analysis of all data sets unveiled that $\mathrm{CaM}$ has two independent sites of different affinities for dCRY ( $K_{\mathrm{d}}$ in nanomolar and micromolar ranges). The lower-affinity site showed also a weak interaction with INAD (adapted with permission from Zhao et al., 2015, published in Frontiers in Molecular Neurosciences). 
2

3

4

5

6

7

8

9

10

11

12

13

14

15

16

17

18

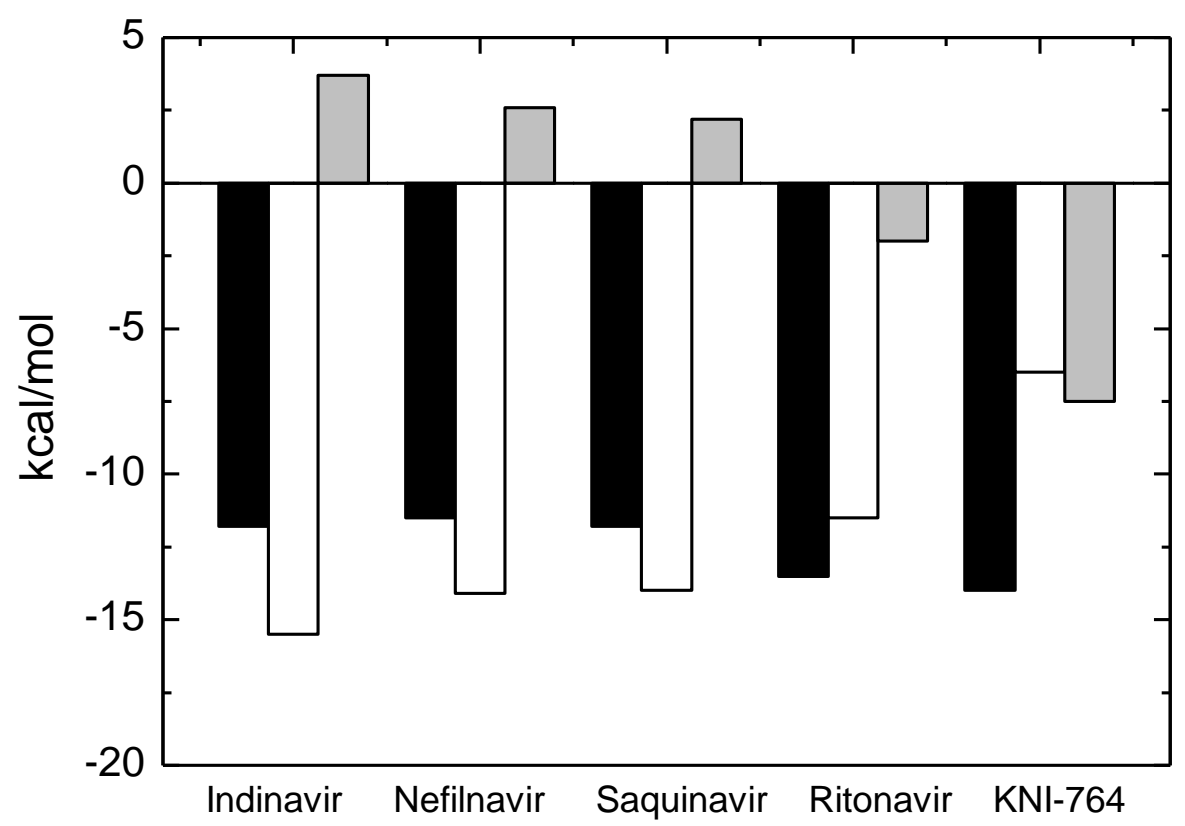

Figure 4. Dissection of the binding energetics of KNI-764 and clinical inhibitors Indinavir, Nefilnavir, Sequinavir and Ritonavir to the HIV-1 protease. Black bars, $\Delta G$; white bars, -T $\Delta \mathrm{S}$; grey bars, $\Delta \mathrm{H}$ (adapted from Velázquez-Campoy et al., 2001, published in Archives of Biochemistry and Biophysica). Unlike the clinical inhibitors, which bind with unfavourable or slightly favourable enthalpy changes, binding of KNI764, effective against resistant mutants, is strongly exothermic. 
(a)

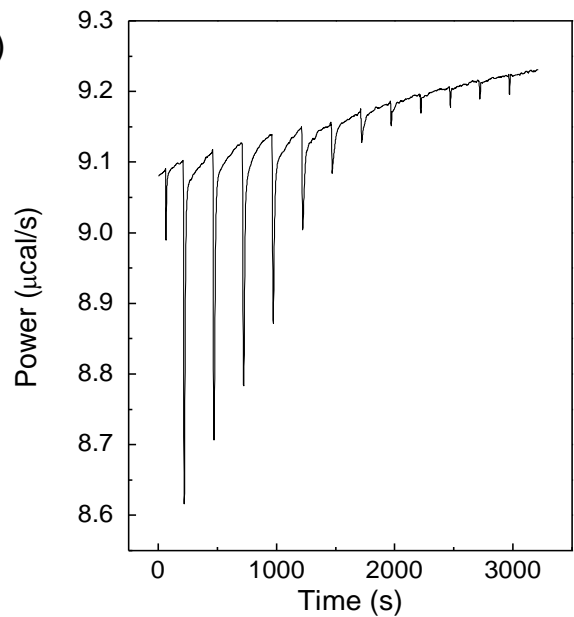

(b)

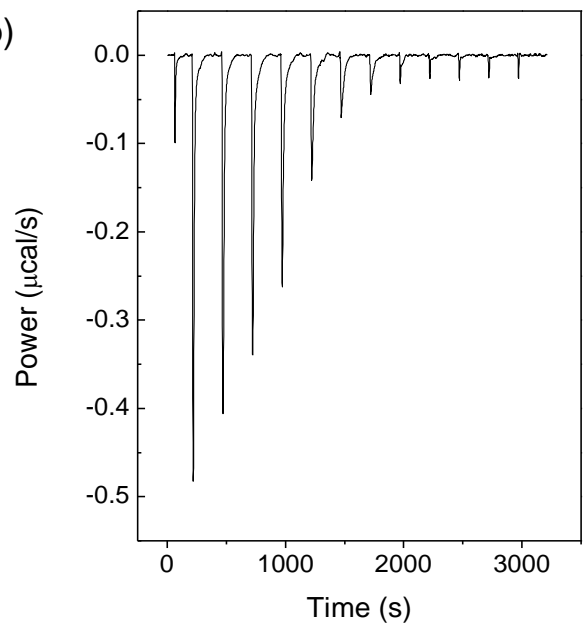

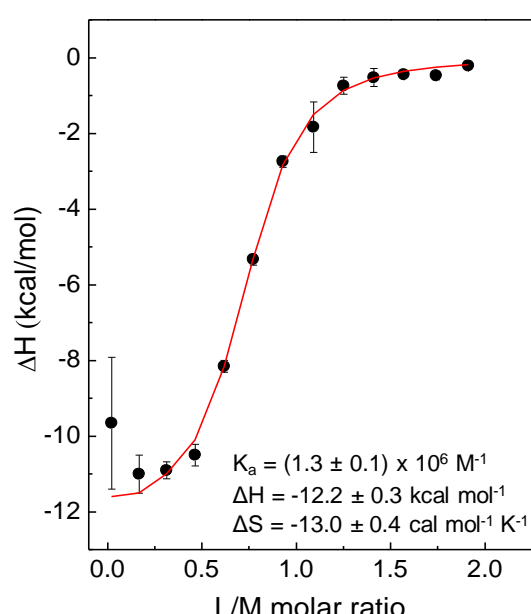

(c)

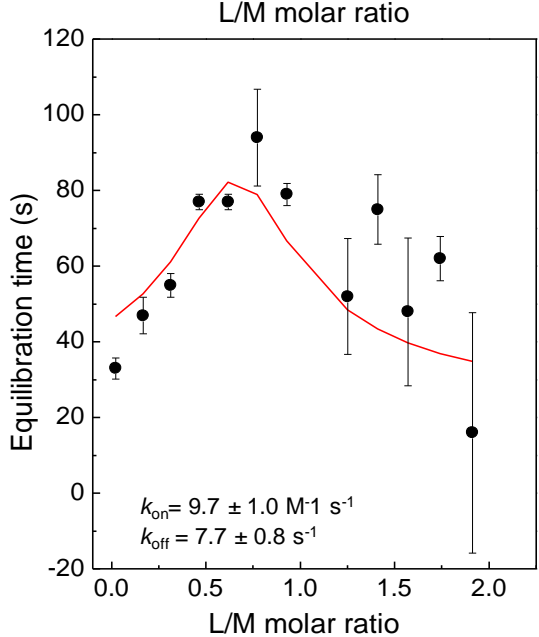

(d)
1

2

3

4

5

6

7

8

9

10

11

12

13

14

15

16

Figure 5. ITC data of a $1: 1$ binding interaction used for thermodynamic and kinetic analysis with kinITC-ETC. (a) The raw thermogram. (b) The processed thermogram after baseline correction and noise removal. (c) Binding isotherm resulting from integration of the processed thermogram as a function of $[\mathrm{L}]_{T} /[\mathrm{M}]_{T}$ (total molar ratio) with integration error bars. (d) Equilibrium time curve showing the equilibration time for each injection as a function of $[L]_{T} /[M]_{T}$. Solid lines in (c) and (d) are the results of globally fitting the binding isotherm and the time equilibration curve with kinITC-ETC. Best fitting parameters are shown in respective panels. 
(a)

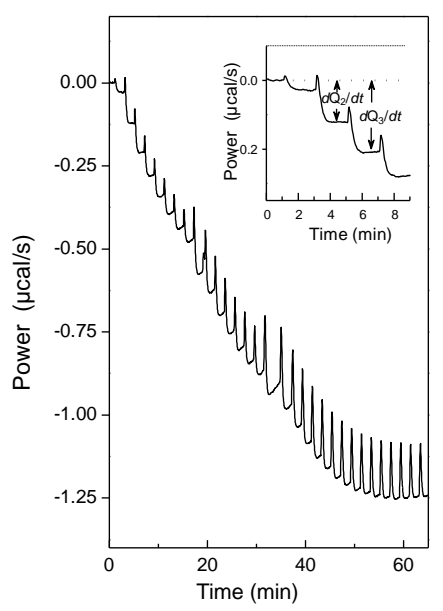

(b)

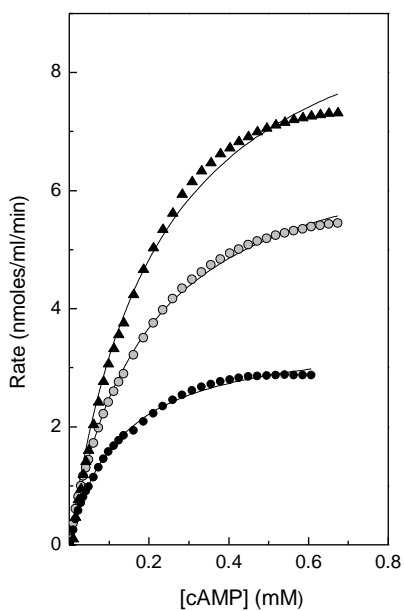

(c)

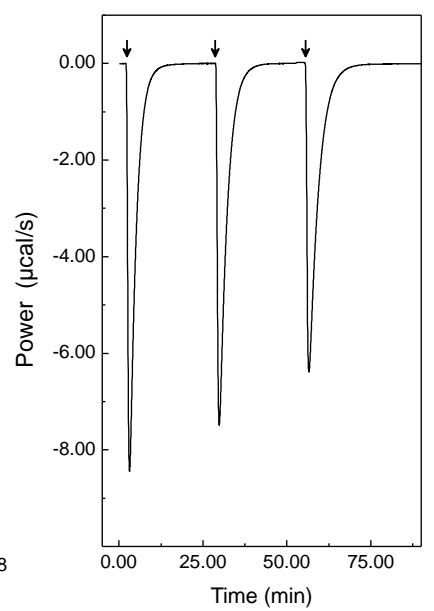

1

Figure 6. cAMP hydrolysis by CaM-dependent PDE1 (3',5'-cyclic nucleotide phosphodiesterase1) determined by ITC. (a) PDE1 (0.04 units) was allowed to reach thermal equilibrium at $37{ }^{\circ} \mathrm{C}$ in the presence of $3.8 \mu \mathrm{M}$ wild-type CaM. Then, serial injections of CAMP (4.7 mM) were made every 120 s. To avoid distortions due to dilution events, the power change associated with substrate addition at injection " $i$ " was average over the $30 \mathrm{~s}$ immediately before next injection. (Inset) close-up view of baseline shift in the three first injections $(1 \times 1 \mu \mathrm{l} ; 2 \times 2 \mu \mathrm{l})$. (b) Rate vs cAMP concentration curves, obtained from the baseline shifts using Eqn. [7] and corrected for enzyme concentration dilution, were fit to the Michaelis-Menten equation (solid lines) to obtain $k_{\text {cat }}$ and $K_{\mathrm{m}}$ from titrations carried out in the absence (black circles) and presence of CaM wild-type (black triangles) and of phospho-(Y)-mimetic CaM Y99D/Y138D double mutant (grey circles). CaM increases $V_{\text {max }}$ without altering the $K_{\mathrm{m}}$, the effect being higher for phosphorylated CaM wild-type. (c) The thermogram represent the instrument response produced by CAMP hydrolysis reaction. PDE1 (0.1 units) was loaded in the sample cell and $15 \mu$ of CAMP (4.7 mM) was injected and the reaction was monitored until the baseline returned to the initial level. Numerical integration of the area under the peak gave $\Delta$ Happ. Two additional injections were made at intervals indicated by the arrows; the decrease in the maximal deflection of the heat flow signal in successive injections was indicative of partial product inhibition (see Stateva et al. 2015 for details). 


\section{洗}

Table 1: Common protocols and software packages not provided by ITC manufactures

\begin{tabular}{|c|}
\hline Protocol \\
\hline Direct titration \\
\hline Multi-injection titration \\
\hline $\begin{array}{l}\text { Continuous isothermal titration } \\
\text { (SIM) }\end{array}$ \\
\hline Heterodimer formation \\
\hline Monomer-dimer equilibrium \\
\hline Displacement titrations \\
\hline $\begin{array}{l}\text { Theoretical analysis of ligand } \\
\text { competition by displacement ITC }\end{array}$ \\
\hline $\begin{array}{l}\text { Three-experiment evaluation of } \\
\text { tight- and low-binding by ligand } \\
\text { competition }\end{array}$ \\
\hline $\begin{array}{l}\text { Single-experiment evaluation of } \\
\text { high-affinity hydrophobic ligands }\end{array}$ \\
\hline $\begin{array}{l}\text { Single-experiment displacement } \\
\text { for tight binding evaluation }\end{array}$ \\
\hline
\end{tabular}

\section{Binding coupled processes}

Coupled proton transfer process

Ligand-induced conformational change

Binding-linked protein folding

\section{Parameters}

$\mathrm{K}_{\mathrm{a}}(\Delta \mathrm{G}), \Delta \mathrm{H}, \Delta \mathrm{S}, n$

$\mathrm{K}_{\mathrm{a}}(\Delta \mathrm{G}), \Delta \mathrm{H}, \Delta \mathrm{S}, n$

$\mathrm{K}_{\mathrm{a}}(\Delta \mathrm{G}), \Delta \mathrm{H}, \Delta \mathrm{S}$

$\mathrm{K}_{\mathrm{a}}(\Delta \mathrm{G}), \Delta \mathrm{H}$, and $\Delta \mathrm{S}$ of dimerization

\section{Reference}

Velázquez-Campoy et al., 2004 Freyer and Lewis, 2008

Markova and Hallén, 2004

Velázquez-Campoy et al., 2004

Burrows et al., 1994
$\mathrm{K}_{\mathrm{a}}(\Delta \mathrm{G}), \Delta \mathrm{H}$, and $\Delta \mathrm{S}$
Zhang and Zhang,1998

(both ligands)

$\mathrm{K}_{\mathrm{a}}(\Delta \mathrm{G}), \Delta \mathrm{H}$, and $\Delta \mathrm{S}$

(both ligands)

$\mathrm{K}_{\mathrm{a}}(\Delta \mathrm{G}), \Delta \mathrm{H}$, and $\Delta \mathrm{S}$

(both ligand)

$\mathrm{K}_{\mathrm{a}}(\Delta \mathrm{G}), \Delta \mathrm{H}$, and $\Delta \mathrm{S}$

(both ligands)

Sigurskjold, 2000

Velázquez-Campoy et al., 2004

Krainer et al., 2012

Krainer and Keller, 2015

Number of protons exchanged $\left(n_{\mathrm{H}+}\right)$; buffer-independent $\Delta \mathrm{H}$ Intrinsic binding parameters

Velázquez-Campoy et al., 2004

Velázquez-Campoy, 2015

Global thermodynamic parameters using a general thermodynamic model

Sahu et al., 2016

Analysis software available at https://scholarsphere. psu.edu/downloads/5712mr21f

\section{Kinetic analysis of ligand binding}

Thermodynamic and kinetic analysis of ITC experiments with kinITC-ERT (single-step binding)

Thermodynamic and kinetic analysis of ITC experiments with kinITC

$\mathrm{K}_{\mathrm{a}}(\Delta \mathrm{G}), \Delta \mathrm{H}$, and $\Delta \mathrm{S}$

$k_{\text {on }}\left(10^{3}-5 \cdot 10^{5} \mathrm{M}^{-1} \mathrm{~s}^{-1}\right), k_{\text {off }}$

$\mathrm{K}_{\mathrm{a}}, \Delta \mathrm{H}, \Delta \mathrm{G}, \Delta \mathrm{S}$, $k_{\text {on }}, k_{\text {off }}$
Muñoz et al., 2019

Burnoff et al., 2012

Vander Meulen et al., 2016

http://www-ibmc.ustrasbg.fr:8080/webMathemati $\mathrm{ca/kinITCdemo/}$

Todd and Gomez, 2001

Freyer and Lewis, 2008

Drazckowski et al., 2016

\section{Enzyme catalyzed reactions}

Measurement of enzyme kinetic constants; Evaluation of activity regulators

Collection and analysis of enzyme
$\mathrm{V}_{\max }\left(\mathrm{k}_{\text {cat }}\right), \mathrm{K}_{\mathrm{m}}$

$K_{i}$ (mechanism of action)

$\mathrm{K}_{\mathrm{i}}$ and IC50 values

Step-by-step conversion of
Demarse et al., 2013 


\begin{abstract}
kinetic data using the single injection method
\end{abstract}

Complete characterization of enzyme inhibition in a single ITC experiment

\section{Screening of fragment-based libraries for lead discovery using nanocalorimeter arrays}

\section{Software for ITC analysis}

SEDPHAT
http://sedfitsedphat.nibib.nih.gov/
software
(free download)
AFFINImeter
https://www.affinimeter.com/site/
itc/

\section{NITPIC}

http://biophysics.swmed.edu/MBR /software.html (free download)

pytc (Pythom-based)

http://github.com/harmslab/pytc

(free download)

\begin{abstract}
raw heat data into kinetic parameters of MichaelisMenten model
\end{abstract}

$k_{\text {cat }}, K_{\mathrm{m}}, K_{\mathrm{i}}$ and inhibition mode

$k_{\text {cat }}, K_{\mathrm{m}}$ (substrates), $K_{\mathrm{a}}, K_{\mathrm{i}}$

(competitive inhibitors) of medium/low affinity compounds

\section{Global multi-method analysis} of data from different ITC data sets or complementary biophysical disciplines using one single model

\section{Global thermodynamic} analysis of ITC data. Easy user-definition of new binding models

$k_{\text {on }}$ and $k_{\text {off }}$ (kinITC-ERT)

Automated and precise serial integration of unlimited number of ITC data sets

Global fit of multiple ITC data sets. User implementation of new binding models di Trani et al., 2018

Recht et al., 2016

Zhao et al., 2015

Brautigam et al., 2016

Tutorials and help available on line

Dumas et al., 2016

Muñoz and Piñeiro, 2018

Piñeiro at al., 2019

Tutorials and model information available on line

Keller et al., 2012

Scheuarmann and Baritigam, 2015

Duvvuri et al., 2018

Model information and tutorials available on line

\section{Glossary}

Activation energy In chemical kinetics, the activation energy (Ea or Gibbs energy of activation $\Delta \mathrm{G}^{\ddagger}$ ) is the minimum energy required to start a chemical reaction and represents difference between the reactants and the activated complex or transition state. It determines the exponential factor of the Arrhenius equation for the temperature dependence of reaction rates $(\boldsymbol{k}=\mathrm{A} \exp (-\mathrm{Ea} / \mathrm{RT})$, where $k$ is the rate constant and $\mathrm{A}$ the preexponential term).

Activation enthalpy The minimum amount of enthalpy $\left(\Delta \mathrm{H}^{\ddagger}\right)$ needed to start a chemical reaction $\left(\Delta \mathrm{H}^{\ddagger}=\mathrm{Ea}\right.$

Activation entropy The activation entropy $\left(\Delta S^{\ddagger}\right)$ is the change in entropy when the reactants change from

7 their initial state to the activated complex or the transition state. It determines the preexponential factor $A$ of the Arrhenius equation.

8 Enthalpy of binding The enthalpy change $(\Delta \mathrm{H})$ accompanying the binding process. It is equal to the heat absorbed or released in the process when it takes place at constant pressure. Entropy of binding The entropy change $(\Delta S)$ accompanying the binding process. Entropy is a measure of the disorder of a system.

Gibbs free energy of binding The change in the Gibbs free energy $(\Delta G)$ coupled to the binding process. It is equal to the energy exchange upon binding and determines the binding affinity $\left(\Delta G=-R T \ln K_{a}\right)$, where $R$ is the gas constant, $\mathrm{T}$ the absolute temperature and $\mathrm{K}_{\mathrm{a}}$ the binding equilibrium constant). 
Table 2. Selection of case studies and reviews illustrating ITC applications to analyze biomolecular interactions

\begin{tabular}{l} 
System/Process \\
Enzyme-inhibitor \\
Protein-metal ion \\
RNA-small molecule \\
(alkaloid) \\
DNA-ligand \\
\hline
\end{tabular}

Protein-carbohydrate

\section{Protein-glycoconjugate} multivalent interactions

Protein-polyelectrolite (PE)

Monomer-dimer
equilibrium
$\begin{aligned} & \text { Binary and ternary } \\ & \text { protein multisite } \\ & \text { interactions }\end{aligned}$
$\begin{aligned} & \text { Binding-linked equilibria } \\ & \text { (ligand-induced } \\ & \text { conformational change) }\end{aligned}$
Protein-terpene
interactions

\section{Binding-linked equilibria}

\section{Summary}

Thermodynamic, kinetic and structural parametrization of human carbonic anhydrase interactions towards enhanced inhibitor design

Special issues for ITC studies.

Thermodynamics of complex formation. Competing and coupled reactions. Buffer protonation and metal-buffer complex thermodynamics

Advances in thermodynamic and structureactivity correlations of RNA-targeted drugs Advances in thermodynamic characterization of DNA-ligand interactions. Binding coupled events. Analysis of complex binding modes

Thermodynamics of bacterial lectin BC2L-A interaction with monosaccharides, disaccharides and bacterial oligo- and polysaccharides

Thermodynamics of lectin binding to multivalent synthetic carbohydrates, mucins and glycoproteins. Microscopic binding parameters. Negative cooperativity among glycan-epitopes

Thermodynamic analysis and driving forces of protein interaction with lineal PE and PEmodified nanoparticles as a guide for PEbased system application

Interleukin-8 monomer-dimer equilibrium thermodynamics ( $K_{\text {dim }}, \Delta H_{\text {dim }}, \Delta S_{\text {dim }}$ )

Evaluation of negative and positive cooperativity by global analysis of ITC titrations in different configurations to follow binary and ternary complex formation

Evaluation of intrinsic binding parameters of homotropic and heterotropic model systems using binding polynomial

ITC-based multi-step binding model of testosterone to sex hormone binding globulin (SHBG)

Complete characterization of HIV aspartic protease inhibition by entothiapepsin. Net proton exchange; and buffer-independent thermodynamic parameters. Individual contributions of enzyme and inhibitor residues to total $\Delta G$

\section{Reference}

Linkuviené et al., 2018

Quinn et al., 2016

Kumar and Basu, 2016

Buurma and Haq, 2007

Marchetti et al., 2012

Dam et al., 2016

Wang et al., 2019

Burrows et al., 1994

Houtman et al., 2007

Velázquez-Campoy, 2015

Zakharov et al., 2015

Gómez and Freire, 1995 
Recombinant proteins

Characterization of
extremely tight ligand-
receptor binding by
competition ITC

Characterization of lowaffinity ligand-receptor binding by competition ITC

Enthalpy screen of drug
candidates

\section{Titration in complex} media (suspension of bacterial cell extract)

Ligand-membrane
protein interaction
studies
Drug partition and
translocation in model
lipid membranes

Surfactant micellization;
association with
biopolymers and
colloidal particles

Biomolecule-
nanoparticle (NP)

Natural product
interactions

Receptor-agonist interaction in living cells
Evaluation of protein quality (binding-active fraction). Effects of purification tags

\section{Determination of HIV-1 protease inhibitor} binding parameters $\left(\mathrm{K}_{\mathrm{a}} \sim 10^{10} \mathrm{M}^{-1}\right)$ Evaluation of $\mathrm{Zn}^{2+}$-dependent association of sensor protein RsrA to sigma factor $\left(\sigma^{R}\right)$ $\left(K_{a}>10^{9} \mathrm{M}^{-1}\right)$. Identification of a new mechanism of oxidative stress regulation

Determination of ligand binding parameters to tyrosine phosphatase $1 \mathrm{~B}\left(K_{\mathrm{a}} \sim 10^{3} \mathrm{M}^{-1}\right)$

Thermodynamic profiling of drug candidates; binding driving forces

Thermodynamics of binding $\left(K_{\mathrm{a}}, \Delta H\right.$, and $\mathrm{T} \Delta S$ ). Assessment of site locus by ITC competition experiments

Thermodynamic signature $\left(K_{\mathrm{a}} \sim 10^{2} \mathrm{M}^{-1}, \Delta H\right.$, $\mathrm{T} \Delta S$ and $n$ ). Challenges of experimental setup and data analysis

Kinetics and thermodynamics of chlorpromazine interaction with lipid bilayers. Intrinsic partition coefficients $\left(K_{\mathrm{p}}\right.$, $\Delta H$ and $\Delta S$ )

Micellization thermodynamics. Binding models. Association mechanisms

Main driving forces for NP-biomolecule interactions. Relative effects of different NP properties on binding

Overview of ITC applications to investigate natural product interactions with proteins, nucleic acids, oligosaccharides and other receptors

Characterization of metabotropic glutamate receptor (mGluR1a) interaction with agonist (DHPG); evaluation of number of binding sites per live cell
Baranauskiene et al., 2019, and references herein

Velázquez-Campoy et al., 2001

Rajasekar et al., 2016

Zhang \& Zhang, 1998

\section{6}

Klebe et al., 2015

Kim et al., 2017

Rajarathnam and

Rösgen, 2014

Martins et al., 2012

Loh et al., 2016

Huang and Lau, 2016

Callies and Hernández

Daranas, 2016

Ikeda et al., 2013
1

2

3 